ENTREVISTA

\title{
LIDANDO COM A ORIGINALIDADE
}

Jane Guyer

\begin{abstract}
Jane Guyer é professora "George Armstrong Kelly" do Departamento de Antropologia da Johns Hopkins University. Em 2008 foi indicada para a Academia Norte-americana de Ciências, e no ano de 2012 recebeu a máxima distinção outorgada pela Associação de Estudos Africanos. Nascida na Escócia, desenvolveu carreira acadêmica principalmente nos Estados Unidos. O seu trabalho é reconhecido por ter revolucionado a etnografia da África Central e Ocidental e por ter colocado uma nova agenda para os estudos antropológicos da economia. Seus artigos e livros tratam dos dilemas da África contemporânea (conflitos políticos e nacionais, instabilidade econômica e monetária, dificuldades no aprovisionamento de alimentos) em diálogo criativo com as tradições antropológicas africanistas e em conversas interdisciplinares densas, principalmente com historiadores e economistas.
\end{abstract}

\author{
Guyer hoje é reconhecida por \\ ter contribuído de forma decisiva \\ para a renovação da antropologia do \\ dinheiro e dos mercados, das relações \\ entre moralidade e economia e entre \\ antropologia e história. Esta entrevista foi \\ concedida a Federico Neiburg, Fernando \\ Rabossi e Gustavo Onto no dia 19 de maio \\ de 2011, no Rio de Janeiro, por ocasião \\ da sua participação no Colóquio "Novas \\ Perspectivas em Etnografia Econômica: \\ modalidades de troca e de cálculo \\ econômico", organizado pelo Núcleo \\ de Pesquisas em Cultura e Economia, \\ no Programa de Pós-Graduação em \\ Antropologia Social do Museu Nacional. \\ Tradução de Juliana Pamplona.
}


Fernando Rabossi - Para começar, você poderia nos falar um pouco sobre a sua trajetória? Você estudou sociologia na LSE (London School of Economics), certo?

Jane Guyer - Bem, a graduação naquele tempo tinha que ser em sociologia com especialização em antropologia. Não era possível ter um diploma apenas em antropologia social. Tínhamos, inclusive, que cursar economia como habilitação. Todos os programas disciplinares eram compostos dessas combinações de ciências sociais. Quando fiz sociologia, tive que cursar demografia, teoria social, política social, estatísticas sociais, todas as subdivisões clássicas da sociologia. E, em seguida, havia uma escolha: poderíamos seguir o caminho da antropologia ou da política social. E eu escolhi o da antropologia.

Gustavo Onto: Isso foi nos anos 60. Quem estava lá naquele tempo?

Eu comecei em 1962. O chefe de departamento era Raymond Firth. Havia o Morris Freedman, que dava o curso de Estudos da China. Anthony Forge, que dava Arte e Nova Guiné. Robin Fox, que dava aulas sobre parentesco. Lucy Mair, que era africanista. E Herbert Morris que trabalhava com Indonésia. Então, na verdade, me especializei em China na graduação. Fiz trabalhos monográficos sobre a China porque o meu orientador no último ano foi o Morris Freedman. Eu nunca tinha ido à China. Conhecia apenas o que havia lido e estudado. Bem, Freedman era o especialista em relações de parentesco na China. Eu estava trabalhando a partir de sua agenda. Era bastante tradicional. Era sobre o que havia acontecido com as formas sociais da China tradicional sob o comunismo. Este era um grande tópico no momento.
Federico Neiburg - No seu tempo de graduação, qual era a sua percepção do campo antropológico britânico?

Era uma antropologia social britânica muito consciente de seu campo naquele tempo, de certa forma se diferenciando dos EUA. As pessoas percebiam que se tratava de um tipo diferente de antropologia. As pessoas estavam interessadas em antropologia francesa - Lévi-Strauss já tinha publicado o seu livro sobre as estruturas do parentesco, em 1949, em francês. É incrível lembrar que An essay on the gift [O ensaio sobre a dádiva] de Marcel Mauss só foi traduzido para o inglês nos anos 1950. Então, era só o começo da enorme influência da escola durkheimiana e dos seus descendentes. Eles foram influências importantes para Evans-Pritchard, para Mary Douglas, que estavam no alto escalão da academia em antropologia quando eu era estudante na graduação. Nós lemos O ensaio sobre $a$ dádiva em inglês, e é claro que Durkheim foi uma figura muito importante. Mas havia uma percepção de que a antropologia social britânica estava se ocupando de temas muito particulares, os temas da vida moral da tradição durkheimiana. Então, havia a consciência de que era uma escola do pensamento naquela época, por mais que estivessem também ali os começos das diferenças, a competição e, na verdade, debates entre três ramificações da antropologia.

Havia a escola de Cambridge em antropologia política, ou seja, Meyer Fortes. Além disso, havia Evans-Pritchard, em Oxford, que fora muito importante no desenvolvimento da antropologia e religião, cultura e linguagem. E, ainda, havia a Escola de Manchester, que estava se formando e se tornando muito influente, uma vez que o grupo de antropólogos ligado a Max Gluckman voltou para a Grã-Bretanha vindo da África, onde fundou o 
Instituto Rhodes-Livingstone na Rodésia do Norte. Eles voltaram como um grupo para fundar uma linha específica da antropologia interessada na vida da metade do século XX: a urbanização, a África industrializada, competição, estratégias, esse tipo de abordagem antropológica. E Fredrik Barth, que retornava da Noruega, também era muito influente. A University College London já estava focando na vida material, através de Daryll Forde.

$F R$ - Todas essas influências já estavam de certo modo presentes?

Sim, elas estavam presentes. Fredrik Barth realizou seus famosos seminários "On Models of Social Organization" [Sobre modelos de organização social] que foram publicados e desencadearam pensamentos novos sobre trocas. Ele lecionou na LSE. Eu estava lá, ouvindo. Ele era carismático, fascinante.

\section{FR - Como você chegou aos Estados Unidos?}

Por um acaso da vida. Um acaso muito afortunado. Eu me graduei e fui para os Estados Unidos visitar uns amigos e acabei ficando e me casando com Bernard Guyer, um americano nascido no Uruguai. Aconteceu que, no lugar onde ele estava, a escola de medicina da University of Rochester, havia um departamento de antropologia com muitos professores antigos que haviam estudado no passado em Cambridge, na Inglaterra. Então, quando eu entrei como aluna na pós-graduação, eu já conhecia boa parte da bibliografia que eles exigiam dos alunos de pós-graduação. Eu estava adiantada no programa deles e fui fazer o meu trabalho de campo muito cedo, muito jovem. Assim, fiz o meu doutorado em Rochester sob a orientação de Robert Merrill.
FN - Você escolheu África em Rochester?

Sim. Eu acho que ao crescer na Grã-Bretanha, nos anos 1950 eu era uma criança na escola, a independência das colônias era a coisa mais emocionante que estava acontecendo no mundo. Era muito presente em nossas vidas públicas, em nossos jornais e tínhamos visitas o tempo todo de lideranças dos vários movimentos políticos. E a Índia, é claro, tornou-se independente em 1947. Houve uma onda crescente de interesse pelos movimentos de libertação entre todos nós. Os movimentos eram muito emocionantes para nós, gente jovem, pensando que o mundo iria realmente mudar.

O livro Os condenados da Terra, de Frantz Fanon (The wretched of the Earth) foi publicado em inglês; havia a guerra na Argélia e, é claro, foi uma parte muito presente na nossa educação política. Então, de certa forma, as lutas dos povos coloniais pareciam ser a coisa mais interessante para o futuro. Mas isso era predominantemente na Inglaterra. Os EUA já estavam avidamente envolvidos no movimento dos direitos civis, no movimento da guerra do Vietnã, no movimento feminista. Havia também a sensação de um movimento rumo a um futuro com muito mais liberdade, mas o foco na África era menor do que na Inglaterra. Entretanto, a partir da minha própria história, a África parecia mais próxima e familiar, me parecia ser o lugar com o qual eu tinha afinidade por ter passado a infância na Grã-Bretanha numa determinada época, e foi por isso que pensei que seria muito interessante ir para a África.

\section{FR - E por que a Nigéria?}

Bem, estando casada, eu e meu marido iríamos juntos, e ele era um estudante de medicina. Portanto, tínhamos que en- 
contrar um local onde ambos pudessem trabalhar, certo? Tentamos duas comunidades universitárias diferentes na África, uma em Uganda, Kampala University - e também na Nigéria. Eram estas as duas melhores universidades na África anglófona naquele tempo, de modo que nós dois poderíamos fazer trabalhos avançados, porque eu ainda precisava estar sob orientação. Eu estava sendo orientada por um professor de sociologia na Nigéria como aluna da pós-graduação. E ele, é claro, como estudante de medicina, também precisava estar sob orientação, no caso, no departamento de pediatria. Nigéria foi o lugar que funcionou para ambos nesse sentido, então fomos para lá. Mas isso foi durante a guerra civil nigeriana e, quando chegamos, com toda a nossa bagagem, os militares nos cumprimentaram no aeroporto. Foi bastante intenso, na verdade. Fiquei lá por um ano.

FN - Como você se preparou para viajar? Você tinha contato com as universidades? Você se lembra dos lugares que visitou, das pessoas que conheceu?

Bem, eu poderia me mover por conta própria em função dos contatos que eu tinha com alguns britânicos. Porém, era muito óbvio que eu precisava da orientação desse professor nigeriano específico, Frances Okediji, que era muito conhecido no campo de estudos sobre famílias. E meu marido, é claro, precisou estabelecer contatos através de redes médicas, numa situação que incluía uma orientação profissional reconhecida. Então, tínhamos que decidir exatamente o que iríamos fazer, não estava dado de antemão. Eu tinha uma proposta de pesquisa e uma bolsa de estudos pequena, mas onde exatamente eu realizaria a pesquisa não estava definido na proposta naquele momento.
Quando chegamos, tivemos que descobrir onde iríamos ficar. Havia um experimento em curso no Departamento de Medicina da University of Ibadan, no sentido de ter um posto avançado da universidade numa área rural, numa pequena cidade, onde os estudantes de medicina poderiam fazer a formação em problemas e questões da saúde rural, e onde eles também poderiam fazer a coleta de dados básicos de saúde pública. Esse centro universitário era recém-fundado, foi bem no início de sua existência. À época, parecia aos nossos amigos que a University of Ibadan era um bom lugar para o meu marido, porque ele poderia trabalhar nas áreas rurais, fazer sua pesquisa e ainda estar sob supervisão médica. Quanto a mim, eu só precisava estar numa área rural em qualquer lugar para fazer o meu trabalho. Então era perfeito. Nós fomos juntos para lá.

$F N-E$ quais eram suas ideias antes disso em termos de objetos de pesquisa possíveis?

Bem, eu havia sido muito influenciada pelo livro Pul Eliya, de Edmund Leach, que passou do Political systems of Highland Burma para esse estudo sociopolítico extremamente detalhado e objetivo sobre o sistema de produção. Aliás, eu havia feito um dos meus textos para exame de qualificação sobre o livro Pul Eliya e eu gostava muito da forma atenta como ele se aproximava do empírico. Então, a minha proposta foi escrita para realizar esse tipo de documentação nos termos teóricos do "ciclo de desenvolvimento de grupos domésticos", que havia sido uma iniciativa de Cambridge, publicada em livro por Fortes e Goody. Aproximadamente no mesmo período, em 1965, o trabalho de A. V. Chayanov, The theory of peasant economy, foi traduzido para o inglês pela primeira vez. Antes disso 
havia uma versão em francês, mas sem muita circulação na academia anglófona.

Eu estava muito interessada em pensar sobre este referencial teórico para um ciclo de desenvolvimento que era basicamente demográfico: sobre a relação entre adultos e dependentes e como ela se estabelecia ao longo do tempo, em relação ao modelo de Goody-Fortes do ciclo de desenvolvimento, que era jurídico-político e que tinha a ver com a posição da unidade doméstica em contextos políticos e sociais mais amplos. Eu havia tomado este tema para mim, como tema para o meu trabalho e, em seguida, o pensamento empírico nos termos do $\mathrm{Pul}$ Elyia de Leach como exemplo do que é possível ser feito.

FR - Como esse tipo de projeto foi recebido em Rochester? Pergunto isso porque não era muito americano, não era muito "cultural", estava mais próximo do modelo britânico.

Sim, tem razão. A liderança daquele departamento havia sido treinada em Cambridge. Foi um acaso da história pessoal, mas também teve o fator extraordinário da sorte implicado. Para que eu pudesse ir com meu marido, de qualquer maneira, teria de ser naquele ano específico, antes da graduação dele na Faculdade de Medicina. Uma vez ele se graduasse, estaria sujeito ao alistamento militar, pois durante a guerra do Vietnã todos os médicos eram convocados. Ele teve que fazer uma equivalência para isentar-se do serviço militar, e não podia simplesmente escolher para onde queria ir. Então, tive que ser ágil no meu processo para que ele pudesse tirar um ano da Faculdade de Medicina para fazer sua pesquisa. Portanto, tecnicamente, ele não estaria apto para o alistamento durante aquele ano. Nós nos vimos nessas circunstâncias afortunadas por acaso. Por eu estar numa universidade particular e já ter feito boa parte do estudo considerado obrigatório, pude concluir as exigências do curso em dois anos. Escrevi o meu projeto de tese no meu segundo ano de pós-graduação.

FR - Quando você terminou o seu doutorado, o que fez? Você começou a dar aulas?

Eu comecei a lecionar meio período, porque nesse momento estávamos realmente em função das obrigações militares do meu marido. Não tínhamos escolha quanto ao lugar onde ficar. Foram dois anos, enquanto ele terminava seu estágio e residência como pediatra e, em seguida, teve o tempo do seu compromisso com o alistamento. Então foram quatro anos, na verdade, em que nos mudávamos para onde quer que ele fosse solicitado. Eu trabalhava em período parcial em todos esses lugares e, então, em 1974, porque havíamos gostado tanto de estar na África, decidimos que voltaríamos para lá assim que ficássemos livres para fazer isso. Ele conseguiu um emprego através dos Centros para Controle de Doenças (Centers for Disease Control - CDC), filiado ao governo federal, em Camarões, e nós vivemos lá por três anos, de 1974 a 1977. Fiz pesquisa e dei aulas por lá.

FR - Como foi a experiência de vocês, tanto na Nigéria quanto em Camarões, como pessoas brancas num ambiente pós-colonial?

$\mathrm{Na}$ verdade, os africanos ocidentais em geral não tendem a agir com nenhuma deferência particular, querem conhecer as pessoas como iguais, então é muito agradável, é bom. O único momento em que fiquei um pouco preocupada por nós como americanos foi quando estávamos na Nigéria durante a guerra civil. Cáritas, a Caridade Católica, estava 
se aliando com Biafra e nós estávamos no lado federal da fronteira geográfica, e por toda a família Kennedy ser católica, houve certa suspeita de que os americanos estivessem de alguma forma afiliados com Biafra. Essa suspeita não estava baseada em nenhuma evidência particular, mas começava-se a ter esta impressão porque muitos dos nigerianos orientais são católicos, então, tomava-se cuidado para não cometer desvios em relação à lei, tentava-se manter uma atitute não chamativa. Esta é a única preocupação que lembro que tive.

\section{FN-Seu trabalho de campo foi realizado} no meio desse contexto de guerra civil. Como foi fazer o seu trabalho de campo nessas condições tão conflituosas? A guerra estava muito presente?

Estava presente de modos muito particulares. A guerra em si estava a alguma distância. Estava longe, nunca chegou a nós como uma guerra de armas e tiros. Mas, por exemplo, na área onde eu trabalhava com os fazendeiros, eles fundaram um campo de treinamento militar para recrutas, então, de uma hora para outra, havia uma base militar inteira bem no meio da minha área de campo. Na verdade, isso não me afetou tanto, exceto pelo fato de que todos os caminhões de mercadorias tinham que passar pela base militar para chegar aos mercados. E havia muito poucos caminhões, poucos transportes comerciais, porque todos os veículos que estavam em bom estado eram de alguma forma requisitados para a guerra. O sistema de mercado era desprovido de transporte, assim, os caminhões eram sobrecarregados com mercadorias. Havia sacos amarrados ao lado, havia cabras no topo, havia latas de óleo de palma. Eu costumava viajar sentada em cima de caixas de tomates. Íamos amontoados dessa maneira e, vez ou outra, os oficiais militares paravam um caminhão de mercadorias, falavam com as pessoas, faziam alguma pressão e havia um pouco de ameaça com a presença dessas autoridades. A presença direta das Forças Armadas era mais intimidadora do que propriamente ameaçadora.

O sistema de mercado, no entanto, foi afetado por essa penúria de transportes. As pessoas desenvolveram um conjunto de métodos para tentar evacuar as plantações de modo muito rápido. Havia um toque de recolher nas cidades, você não podia entrar depois das 18 horas, e não podia sair antes das 6 da manhã. Portanto, os caminhões que iam para as áreas rurais e que alimentavam as cidades tinham que sair e voltar em um dia, ou então teriam que permanecer na barreira durante toda a noite após o toque de recolher. Desta forma, nos mercados atacadistas rurais, eles tinham que trabalhar muito rápido para fazer os negócios, encher os caminhões, fazer a troca de dinheiro, se deslocar, certo? E isso era um pouco diferente de quando eu voltei, mais tarde, a esses mercados rurais. Quando voltei, achei mais tranquilo, era organizado de modo menos rigoroso. Antes, havia o efeito da guerra.

Havia também contrabando, estávamos muito perto da fronteira com Benin, então, os contrabandistas costumavam vir através dessa área trazendo produtos: não equipamento militar, até onde eu saiba, mas trazendo mercadorias que estavam em falta nos mercados nigerianos. Mas como eu disse anteriormente sobre ter que manter certa discrição, eu sabia dessas coisas, mas não tentei investigar para ter mais informações sobre isso, pois era potencialmente perigoso tanto para eles quanto para mim. É possível que, àquela altura, o avanço real de Biafra em outras partes da Nigéria tivesse cessado, e que a guerra tenha prosseguido realmente dentro de Biafra, que é uma área 
delimitada. Acho que havia uma sensação de que o lado federal ia ganhar, que era só uma questão de quando e como, e que o perigo físico real na maioria das áreas não seria tão grande, porque era na verdade uma guerra de secessão.

$F R$ - Você teve duas experiências diferentes na África, uma em Camarões e a outra na Nigéria. Você fez pesquisas em ambos os países e também criou relações com as universidades locais. Uma de suas singularidades é o seu extenso trabalho colaborativo com colegas africanos. Você poderia nos falar um pouco sobre os constrastes e as diferenças entre esses dois lugares?

Eu nunca ministrei cursos na Nigéria, eu dava palestras com frequência, além de conferências e atividades do tipo, mas nunca cursos. Já em Camarões eu fui professora, lá eu ministrei cursos. Acho que a minha primeira colaboração foi no contexto de Camarões com Eno Belinga, com o meu trabalho Wealth-in-People (Guyer $\&$ Belinga 1995). De fato, tornei-me mais e mais consciente de como é relativamente estreito o nosso conhecimento sobre esses lugares, mesmo quando fazemos pesquisas, porque nós temos um foco, seguimos e documentamos isso, mas há o contexto maior, o contexto histórico, o contexto linguístico, em toda a África Ocidental, as poéticas da linguagem... Esse é um vasto horizonte e, desde o início, comecei a ter consciência de minhas próprias limitações em relação à vastidão do conhecimento. Portanto, a colaboração foi uma maneira muito estimulante de construir uma visão mais ampla, sem passar por cima de quem eu sou, sem abrir mão do conhecimento com o qual eu me sentia segura.

$F R$ - Você encontrou diferentes maneiras de colaboração: trabalhando junto a acadêmicos, criando e liderando equipes como no projeto Money Struggles (Guyer, Denzer \& Agbaje 2002). Como foi a experiência de estar lá trabalhando com uma equipe?

Bem, Money Struggles foi um projeto de equipe, foi um acontecimento muito feliz. Foi lançado em 2001 nos EUA e, em 2002, na Nigéria. O trabalho de campo se deu em 1997. Mas o que aconteceu nesse caso foi que em 1992 eu já estava desenvolvendo um trabalho sobre dinheiro. Tendo trabalhado com produção e, particularmente, com um abastecimento de alimentos urbanos no interior, tal como a área onde eu estava na Nigéria, fiquei muito intrigada com os preços, especialmente com os preços de comida. Comecei a tentar entender os preços e editei aquela coleção Feeding African Cities (Guyer 1987a), publicada em 1987, para tentar reconstruir o tipo de economia política de diferentes sistemas urbanos através do tempo. Trata-se, portanto, de um livro histórico.

Enquanto eu fazia o que estava fazendo, ficava frustrada com o fato de nós realmente não entendermos por que os preços são o que são, e o que as intepretações sobre preços pareciam sugerir: "Bem, os preços estão altos demais", mas também ,"os preços estão muito baixos". Eu não sei se vocês se recordam, mas houve um momento, durante o início do período de ajustes estruturais, em que o Banco Mundial estava tentando ajustar aspectos variados das economias africanas, mais especificamente através da alteração das taxas de câmbio. E havia um ditado: "temos que acertar os preços". "Acertar os preços" fazia parte da agenda; para provocar o lado da demanda para os produtores e para os consumidores de modo que tivessem condições financeiras para adquirir as mercadorias, e também para os fornecedores e para 
os produtores de alimentos, para que fossem capazes de ganhar a vida com isso. Nunca foi esclarecido como seria possível fazer isso, especialmente com a desvalorização da moeda e uma taxa de câmbio imprevisível.

Era este o contexto a partir do qual eu estava tentando pensar o registro hitórico dos preços. E quando trabalhamos nesses casos históricos, o caso em que trabalhei foi sobre a história de fornecimento de alimentos em Yaoundé (Guyer 1987b); aprendi que toda a parte inicial da história se dava por requisição. Não era feito num sistema de mercado. Pessoas comuns eram simplesmente requisitadas pelos chefes para prover alimentos para a cidade-capital. Na verdade, foi preciso uma série de intervenções para torná-lo um sistema de mercado na década de 1950. Então, eu estava muito intrigada com toda essa questão de preços. E ocorreu-me num determinado momento - afinal de contas eu sou antropóloga "vamos retornar aos próprios valores das pessoas, suas próprias transações comerciais e assim por diante", o que significava para mim voltar historicamente ao sistema de moedas indígenas africanas. Depois, fui trabalhar em Tervuren, Bélgica, no Royal Museum of Central Africa, que tem uma coleção de moedas simplesmente extraordinária. Passei algum tempo lá documentando os diferentes tipos de dinheiro históricos da África Equatorial; há um número surpreendente.

Foi assim que eu acabei trabalhando com dinheiro e tornou-se muito interessante para mim pensar sobre as maneiras como os sistemas de valores com base nessas moedas mudaram ao longo do tempo, especialmente com a sua remoção e substituição por dinheiros coloniais, o que aconteceu em toda a África Central Ocidental. O último curso legal das moedas africanas se deu em 1948, na
Nigéria, em uma enorme campanha para recolhê-las e substituí-las pelo dinheiro colonial. Então, em 1992, eu organizei uma conferência em Gana sobre a turbulência nos sitemas monetários, pensada historicamente, e foi esta a base para Money matters (Guyer 1995), publicado em 1995.

Mas em 1992 nós tivemos uma experiência extraordinária, quando fomos comprar biscoitos no intervalo da conferência com sacos de dinheiro, porque o valor do Ghanaian Cedi havia caído. E nós ficávamos pensando: aqui estamos estudando esse fenômeno historicamente, e não estamos fazendo nada sobre o que está acontecendo agora diante de nossos olhos, o que está acontecendo em nossas próprias vidas. Então, foi aí que começamos a fazer uma coleção de artigos de jornal sobre a economia nigeriana, para ver se nós poderíamos produzir algum tipo de arquivo de materiais, para documentar dia a dia, semana a semana, o que estava acontecendo em uma economia na qual o valor da moeda estava caindo com guinadas imprevisíveis.

LaRay Denzer, uma historiadora radicada em Ibadan, organizou a coleção dos recortes de jornais na Nigéria ao longo de vários anos. E foi com base nessa coleção que eu e LaRay escrevemos uma proposta de pesquisa para a Fundação MacArthur solicitando financiamento, para analisar os materiais e interpretar a turbulência daquela era na economia popular. Eles ligaram um dia para o meu escritório. Estavam numa reunião debatendo a proposta e disseram: "Como vocês podem fazer isso sem o trabalho de campo? Vocês vão fazer todo o estudo a partir de jornais? Como vão fazer isso?". E eles disseram: "Se vocês escreverem uma proposta incluindo o trabalho de campo entre agora e hoje à tarde, nós vamos dar-lhes um 
pouco de dinheiro extra para o trabalho de campo!". Então pensamos: "tudo bem, vamos fazê-lo".

Nós simplesmente abrimos espaço em nossas vidas e escrevemos uma proposta de alguns poucos milhares de dólares, uma quantia muito pequena, e eles nos deram o dinheiro. Então nos confrontamos com a pergunta "O que vamos fazer com isso?". A Nigéria é enorme, existem 250 línguas na Nigéria! "Onde é que vamos começar realmente a implementar esse projeto que elaboramos em poucas horas?". E foi LaRay quem teve uma ideia brilhante. Ela disse: "Por que não podemos simplesmente pegar o dinheiro, montar uma equipe de pesquisadores da Nigéria e dar a todos uma pequena subvenção com esse dinheiro, e assim a gente organiza um empreendimento coletivo?". Assim todo mundo vai fazer alguma coisa relacionada a seu campo de conhecimento, mas apontando-a na direção da desvalorização monetária: estudar o que está acontecendo nos domínios em que cada um já conhece, durante o período da desvalorização. Havia alguém que conhecia o sistema de transportes, alguém que conhecia religião, alguém que conhecia teatro...

GO - Que tipos de perguntas você tinha em mente naquele momento para direcionar esses problemas de pesquisa ligados à inflação, à instabilidade monetária, ao valor do dinheiro e aos "ajustes estruturais"?

Sabe, naquela época havia muito mais desses temas na história social, não tanto na antropologia; não havia muita coisa na antropologia. Talvez houvesse algum pensamento em torno disso, mas não estava bem organizado como um conjunto de trabalhos, havia exemplos, lugares específicos, a entrada do dinheiro ocidental, esse tipo de turbulência à qual se referem novamente Bohannan, Godelier, Meillassoux - todos esses pensadores das "articulações" estavam observando mudanças. Mas eles não estavam necessariamente pensando sobre o mesmo tipo de turbulência que nós estávamos examinando, algo que não era possível determinar para onde estava indo. Nós nem ao menos tínhamos certeza, naquele ponto, sobre que tipo de "articulação" caracterizaria o momento de ajuste estrutural, o que exatamente seria a economia do futuro. Todas essas políticas começaram na África na década de 1980, portanto, antes da globalização, antes da queda do Muro de Berlim, antes da integração da China a este grande movimento na economia mundial. Não era sempre fácil saber com clareza qual era exatamente a bibliografia relevante.

Então foi isso que nós fizemos, nós levamos o dinheiro que tínhamos para a etnografia e o repartimos. Fizemos uma reunião de planejamento com acadêmicos nigerianos muito bons e demos a todos um pequeno auxílio. Nós, que éramos os estrangeiros, não ficamos com muito dinheiro para fazer os artigos, acho que quase nada, e depois ainda fizemos uma conferência para devolver a quantia retirada. Mantivemos contato uns com os outros o tempo todo e tínhamos uma expectativa muita rigorosa: de que cada artigo seria muito empírico, de que estávamos sendo testemunhas de um momento da história que não estava documentado, em parte por causa do regime militar. Todo mundo estava livre para usar qualquer método teórico ou disciplinar que quisesse usar, porque éramos de diferentes disciplinas. E então fazíamos uma conferência para criticar os trabalhos uns dos outros e juntar os textos, transformando esse conjunto em livro. Foi isso que fizemos. E sim, as pessoas gostaram. 
FN - Dinheiro, preços, abastecimento de alimentos, mercados, todos são assuntos econômicos. Naquele tempo, eles também foram alvos das então chamadas políticas de ajuste estrutural, tal como o que reconhecíamos na América do Sul. Que tipo de diálogo você teve com a economia e os economistas? Como é que eles receberam o seu trabalho?

Acho que eles não leram o meu trabalho. Existem dois tipos de posicionamentos de economistas em relação ao meu trabalho. Talvez existam três tipos de posicionamentos. Para alguns, a minha pesquisa não dialoga com seus problemas, então eles olham um pouco de lado: O que é isso? Para que fazer isso sem ter um problema muito específico ao qual se referir? Há uma crítica ao Feeding African Cities em que toda a avaliação é um lamento por este livro não tratar de qualquer "problema". Há um economista que está bastante interessado em apreender as percepções dos antropólogos em geral. Ele tem sido um colega muito próximo, Chris Udry e está em Yale. Ele é um microeconomista bem sofisticado, então ele consegue transformar as percepções dos antropólogos em projetos de pesquisa que podem incluir os tipos de modelos matemáticos que satisfazem às normas de sua própria disciplina. Isto é interessante.

Acho que um terceiro posicionamento seria, portanto, de um grupo entre nós que, através de toda a década de 1980 , estava falando a partir do feminismo e também a partir do etnográfico sobre as limitações do modelo doméstico (household). Se você fala sobre a vida doméstica como uma unidade e não se pergunta quais são os relacionamentos que a unidade contém, você estará obliterando as relações de apoio, de dominação, de restrição ou de possibilidade para os outros membros da família, para além do chefe de família. E mesmo na metodologia, não se pode presumir que o chefe de família conheça a vida econômica de todos os membros. Então, nós estávamos tentando inserir na metodologia que os estudos domésticos e os dos camponeses precisavam que todo mundo na casa fosse entrevistado. E era necessário haver uma teorização quanto ao lugar específico da mulher.

Eu escrevi um artigo em 1981 (Guyer 1981) que foi bastante citado por economistas por muito tempo, porque permitiu que eles tivessem uma visão particular sobre os processos intrafamiliares, visão esta que estava sendo elaborada por antropólogos de modo mais amplo, não apenas por mim. E, assim, para construir seus modelos, esses economistas aplicaram a matemática da teoria dos jogos a esta questão e, de fato, foram muito longe com isso. Um livro foi publicado em 1997 sobre processos intradomésticos e foi escrito por economistas com um componente matemático. Eu contribuí para isso. Eles me convidaram para comentar sobre o trabalho deles numa conferência (Guyer 1997). Há uma nova possibilidade de engajamento entre o tipo de trabalho sócio-histórico que eu fiz e o que é chamado de economia heterodoxa, e espero poder explorar isso. Então, alguns desses intercâmbios e algumas dessas relações entre antropologia e economia são muito interessantes e, por vezes, esses campos apenas passam uns pelos outros sem realmente se afetarem.

FN-Entre a sua tese de doutorado e essa pesquisa no final dos anos 1980, o que exatamente aconteceu com você profissionalmente e pessoalmente? Depois de Camarões, você voltou para os EUA, para a Northwestern University?

Primeiro eu fui para a Boston University. Este é mais um dos grandes acontecimen- 
tos afortunados da minha vida pouco previsível. Muitas decisões foram tomadas simplesmente por que se apresentaram como possibilidades boas e divertidas. Voltamos de Camarões em 1977, porque meu marido teve de retomar a sua carreira em casa. Ele havia feito um trabalho muito interessante em Camarões, mas precisava completar a sua formação pediátrica e abrir caminhos em sua carreira nos EUA. Então nos mudamos para Boston, e eu comecei a realmente me dedicar intelectualmente à história, porque estava muito convencida de que, pela minha experiência em Camarões, o tipo de trabalho clássico e sincronizado para o qual eu tinha sido treinada para fazer não seria o suficiente. Precisávamos da Escola de Manchester e do tipo de história social de E.P. Thompson para os estudos na África.

Para lugares como Yaoundé, onde a história colonial tinha sido tão presente, tão insistente, tão importante na formação e na transformação da economia, da sociedade e da religião, era realmente preciso fazer da história parte do empreendimento antropológico. Então, eu fiz alguns artigos históricos e eles foram os meus primeiros trabalhos publicados em história econômica. Assim, eu tive a sorte incrível de conseguir um emprego como docente iniciante em Harvard em 1980. Trabalhei lá por seis anos. De lá fui para a Boston University, de 1986 a 1994, e em seguida, para Northwestern, de 1994 a 2002. E depois vim para Johns Hopkins.

\section{FN - Como foi a sua leitura naquele tempo dos trabalhos de antropologia econômica, como, por exemplo, os de Bo- hannan, que também trabalhava a partir de uma perspectiva histórica?}

A coisa que aquela geração de antropólogos fez, que foi tão incrivelmente importante, foi esse trabalho empírico bem detalhado. Você podia ler e reler esse trabalho e encontrar pequenos pontos nos quais se podia apreender a história, ou você podia reler a partir de alguma iniciativa nova e notar que algo diferente estava se dando. Porque suas evidências empíricas eram normalmente mais amplas do que suas interpretações. E, de fato, isso era relevante. Lembro-me de que, quando era estudante de pós-graduação, o meu primeiro desafio analítico foi reanalisar um conjunto de trabalhos empíricos publicados para então tomar um viés teórico diferente e reavaliar o que havia sido publicado. Acredito que a expectativa daquela geração foi a de sempre publicar o máximo possível de registros das evidências, mesmo se você, o autor, não fosse capaz de interpretar tudo aquilo. Alguém viria depois. Fazia parte de uma visão científica muito particular que essas pessoas tinham, a de que a evidência pode estar além de sua capacidade de interpretação, mas era preciso que ela estivesse ali para que outra pessoa pudesse futuramente desenvolvê-la.

Este foi um dos desafios que nos foram ensinados como estudantes: que deveríamos voltar aos registros e relê-los, e repensá-los e reanalisá-los, e juntar todos os pedaços novamente, talvez, de uma maneira diferente. Grande parte desse trabalho tinha essa capacidade, abria essa possibilidade, permitia que se voltasse a ele para relê-lo, repensá-lo e reanalisá-lo a partir de uma pergunta mais histórica ou, por vezes, através de uma grande questão, para a qual mesmo um pequeno fragmento de evidência poderia ser importante. E sentia-se a confiança de que, se alguém trabalhasse duro o suficiente, encontraria algo, seria possível reconhecê-lo quando o visse, pois estaria ali. No meu caso, tratava-se de um engajamento menos teórico. Embora desde muito cedo eu tivesse sido 
orientada por um viés histórico, eu estava muito mais interessada no neomarxismo de Claude Meillassoux, Georges Dupré, Pierre-Philippe Reyand - este tipo de escola de pensamento - do que em reproduzir o funcionalismo-estrutural.

FR - Tenho a impressão, ao ouvi-la agora e ao ler o seu trabalho, de que a antropologia não é o suficiente. Quais são as implicações teóricas presentes no modo como você articula etnografia e história?

Eu não diferenciava claramente o que era do meu temperamento e o que se devia às minhas convicções teóricas. Acho que é preciso um bom tempo de carreira para se perceber por que você se interessa pelo que se interessa. Em algum momento, a partir da década de 1990, me tornei consciente de que estava começando a escrever obras que dialogavam diretamente com pessoas específicas, não apenas fazendo comentários teóricos ou tentando estabelecer uma nova fronteira teórica. Mas as pessoas me solicitavam, assim como você me convidou: "Venha para esta conferência, nós gostaríamos que você falasse sobre ' $\mathrm{X}$ ', este é o nosso tema, você tem alguma coisa a dizer sobre isso?". E eu comecei a escrever alguns dos meus trabalhos neste formato, em vez de conduzi-los a partir de um projeto de pesquisa. E então comecei a perceber que havia toda uma série de outros tipos de inspirações e de temperamentos dos quais eu gostava, que me davam alegria. Este modo de pensar talvez tenha abarcado mais essas relações, como no trabalho em equipe, que não só exigia uma estratégia para que se conseguisse fazer o trabalho, como também era uma maneira de encontrar inspiração, triangularizando meu próprio pensamento com o de outras pessoas.

Acho que esta é uma das coisas que eu sempre amei na antropologia, e eu escrevi sobre isso uma vez (Guyer 1999), também como resposta a uma encomenda de texto: é o fato de que estamos sempre falando sobre a originalidade da vida humana e de sua capacidade e imaginação. Isto, é claro, é lido de modo mais convencional como diversidade e todas as culturas do mundo podem ser alinhadas de modo muito particular com o que Ruth Benedict chamou de "grande gama das possibilidades humanas". Mas, de certa maneira, a capacidade de identificar originalidade, acredito que isso esteja inscrito na antropologia desde o início do século XIX e demande um certo tipo de triangulação das ideias, de envio de uma ideia e da escuta de uma resposta, provocando a nossa percepção da originalidade tanto em relação às situações específicas que estudamos quanto aos pensamentos de um outro povo. Aquele artigo em particular foi bastante divertido fazer.

Na verdade, foi o Achille Mbembe que me pediu para escrever. Ele havia sido um ótimo colega no início da década de 1990, um interlocutor muito interessante para os meus trabalhos em Camarões sobre a riqueza-nas-pessoas (Wealth-in-People). Em algum momento, em meados dos anos 90, ele deu uma conferência sobre Estudos Africanos e África, na África do Sul. Ele me pediu para falar sobre o que a antropologia havia oferecido para os estudos africanos ao longo dos últimos 100 anos. "Últimos 100 anos (!?). Isto é um artigo? Uma enciclopédia? O que você está me pedindo para escrever?". Ele disse: "Escreva o que quiser, o que vier à sua mente." Então eu resolvi escrever sobre método: a questão da identificação de originalidade, e de como fazemos isso, quais são os tipos de disciplinas intelectuais que nós temos, treinamento da mente que nos permite reconhecer e, em seguida, documentar e pensar sobre a originalidade, tanto origi- 
nalidade histórica quanto originalidade lateral, cultural. Foi isso que fiz para aquele artigo específico.

FR - Falando especificamente de Marginal gains (Guyer 2004). De certa maneira, este trabalho teve um impacto importante nas discussões sobre África, sobre economia, antropologia do dinheiro. Podemos, talvez, dizer que condensa esses campos de conhecimento dos quais você está falando: relações, historicidade, também dinheiro e cálculo, neste caso. Como você explica o projeto do Marginal gains?

Eu fui convidada para dar as palestras Morgan na Rochester University, em 1997. É claro que estou em casa neste departamento, é o departamento no qual me formei, e ainda estou pensando em formas de articulação. Mesmo que eu ainda não tivesse feito realmente uma obra teórica sobre articulação, isto sempre estivera na minha mente. O tópico que abordei foi: "Limiares e Conversões: Explorações das economias articuladas da África" ("Thresholds and Conversions: Explorations of Africa's Articulated Economies"). Então, eu tive uma série de ideias em torno de articulação que organizei para essas palestras, e o capítulo introdutório foi dedicado a Bohannan e às esferas de trocas, endossando isso, mas também lhe dando maior nuance, de modo que toda a troca parecesse e fosse, de certa forma, assimétrica, potencialmente assimétrica, na verdade, assimétrica. Este foi o meu insight desde o início do projeto. Portanto, estava cruzando história com antropologia, em especial a história das transações monetárias do tráfico de escravos através daquela área da Nigéria central.

Tive que fazer um total de quatro palestras, trabalhei com outros temas específicos que eu já tinha em mente, como o do artigo da análise dos orçamentos domésticos. De uma forma ou de outra, eu havia trabalhado sobre domicílios (households) por 15 anos. Então, fiz uma justaposição de uma série de peças que pareciam possuir certa integridade que eu ainda não havia descoberto. Mas fiz a série de palestras e, em seguida, é claro que tive que escrevê-las para publicação. Quando comecei a escrever, isso se ampliou e se estruturou numa arquitetura diferente do que foram as palestras. Então, eu tive que trabalhar com outros campos conceituais bastante particulares para possibilitar figurar ali uma ideia de conjunto, pelo menos um plano mais coeso, porque é realmente um assunto muito grande para se dar conta em um pequeno livro. Mas eu tive a intenção de mantê-lo pequeno e, de modo muito consciente, cuidei para que cada capítulo tivesse o tamanho de uma palestra, para que contivesse o ponto de partida que era o próprio formato da palestra, sem notas de pé de página. Meus colegas da História ficaram horrorizados: "Você tem todas essas referências, todo esse material e não há notas de pé de página?".

Sabe, à sua maneira, havia ali uma qualidade artística: foi dessa forma que a arquitetura do texto se apresentou para mim e era isso o que eu queria fazer. Mas se pensarmos sobre interlocutores, quase todos os capítulos têm um alguém implícito com quem eu converso ("Como vou fazer isso? O que você acha sobre...?"). Ou seja, desafiando ideias, realmente tentando ir fundo, retomando todas essas linhas que mencionei anteriormente: "a literatura diz isso e, agora, como isso pode ser possível, o que está por trás disso?".

GO - Em termos da recepção do livro Marginal gains, foram muitas as resenhas por parte de africanistas, antropólogos, sociólogos econômicos, como, por exemplo, Michel Callon, e também 
economistas, eu suponho. Eu me recordo de ter lido seu texto que abarca a questão dedicada ao Marginal gains no African Studies Review, em que você tenta responder a alguns comentários sobre $o$ papel do empírico e do teórico no livro (Guyer 2007a). Então, como foi a recepção do livro? E como foi a sua reação?

A maior parte da recepção foi positiva. Acho que ninguém teve um posicionamento hostil em relação ao livro, pelo que eu saiba. É claro que é muito gratificante. Também é importante pelo esforço exigido. Pois acho que, em diferentes disciplinas, há sempre algum subsegmento de nossa comunidade intelectual que quer trabalhar de modo muito imediatista, forjar classificações e seguir em frente. E eu me sinto muito contrária a tudo isso, o mundo é muito mais interessante, tem muito mais a nos dizer do que o que temos como ferramentas conceituais para apreciá-lo. Portanto, o fato de que o livro era tão insistentemente empírico, impedindo que as pessoas simplesmente o decifrassem rapidamente, tal como elas poderiam ter feito com um argumento teórico forte, era uma coisa boa. Foi muito bom ter sido capaz de me posicionar dessa maneira, porque era um desafio. Ou seja, é como dizer para os outros: "se quiser, pode reinterpretá-lo, mas vai ter que lidar com todo esse material empírico e ver o que você pode fazer com ele". Eu tenho uma ótima colega economista que disse: "Meu Deus, quando você pensa sobre todas essas conversões, agora que você as apontou, para onde quer que eu olhe, enxergo conversões, não é?". Há coisas incomensuráveis sendo reunidas.

De certa maneira, acho que uma quantidade relevante de pessoas de diferentes disciplinas reconheceu o fenômeno e disse: "Bem, nós reconhecemos que, de certa maneira, não estamos exatamente acompanhando isso na prática, mas já podemos enxergá-lo". Alguns aspectos foram assimilados muito rapidamente, eu acho, e as pessoas começaram a retomar a ideia de conversão, para voltar a Bohannan, e depois aplicá-la nas finanças modernas. Pessoas como Bill Maurer usaram o meu trabalho desta forma. Houve um momento de absorção muito rápida, penso que isso não se deva a uma qualidade persuasiva, mas sim ao reconhecimento do fenômeno por parte das pessoas. E continua sendo um desafio para mim. É um trabalho inconcluso, ele possui uma completude estética, mas não está encerrado intelectualmente. Agora, estou pensando que trabalhar com a temporalidade é uma coisa que preciso fazer. Porque, de fato, nos EUA, o artigo que fiz mais recentemente, "Prophecy and the near future", foi, de longe, o mais amplamente lido. Acho que isto se deve ao fato de que as pessoas estão se sentindo muito desafiadas pelos fatores temporais (Guyer 2007b).

FN - Qual a sua opinião sobre a chamada Nova Sociologia Econômica? Como você acha que essa literatura específica dialoga com o seu trabalho?

Eu acho que é um trabalho notável, simplesmente extraordinário! Eu não mencionei que há um movimento muito grande nos EUA que não é sobre a África. Há, por exemplo, a Viviana Zelizer, e toda uma série de pessoas fazendo um trabalho absolutamente importante no Ocidente, o que torna este campo muito vivo porque você pode estabelecer novas relações, se deslocar em diferentes direções, cruzando diferentes campos. E há pessoas trabalhando na antropologia de finanças, que também falam comigo como se eu fosse parte de sua rede, mesmo que eu nunca tenha realmente trabalhado diretamente com finanças, exceto talvez nos artigos sobre profecia 
e preço. Mas isso é um pouco por acaso. Não é algo sobre o qual eu tenha desenvolvido um projeto de pesquisa. Mas acredito que o apreço pela novidade, a originalidade do nosso momento histórico no que diz respeito à vida econômica e à valorização monetária estão sendo reconhecidos de forma bem mais ampla do que antes, e isso é muito animador.

Também penso nas pessoas que trabalharam na nova economia institucional e nas pessoas que ficaram muito conhecidas neste tipo de campo, como a Elinor Ostrom, com propriedade coletiva. Eu acho mais importante a sua insistência na questão de que existem modos de gestão coletiva do que exatamente a nova teoria econômica institucional. Creio que a questão é absolutamente instigante e bastante significativa no contexto do trabalho teórico que esteve, por algumas décadas, muito focado na racionalidade da tomada de decisão individual, e assim por diante. Por exemplo, o livro de Avner Greif sobre o comércio do Mediterrâneo é interessante e o material de origem é muito importante para compreender o comércio do Mediterrâneo no início do período moderno. Grande parte é proveniente deste enorme depósito de documentos, a maioria é de comerciantes judeus do Cairo e foi encontrada nesta sala - a geniza - basicamente deixada de lado porque não se pode jogar fora um pedaço de papel que possa ter o nome de Deus nele. Em torno de uma grande quantidade de documentos, não apenas documentos religiosos, mas também contratos, havia a crença de que poderiam estar abençoados, então todos eles foram lançados na geniza e esta geniza do Cairo foi descoberta através da academia do mundo ocidental na década de 1890. Havia esse enorme esconderijo de documentos sobre o qual duas gerações de acadêmicos trabalharam. É um trabalho muito difícil, eu acho que está escrito em várias línguas, em escritura hebraica, talvez em árabe também.

Avner Greif trabalhou nessa coleção a partir da perspectiva da New Institutional Economics, e eu estava tentando entender o sistema monetário, porque o Mediterâneo era um sitema de troca enorme e rico naquele momento particular e um tanto dominado por Veneza. Então, ele ficava falando sobre ducados. Como eu havia trabalhado com um grupo de historiadores que lidavam com múltiplas moedas, eu ficava pensando: "Este é um tipo de ducado real, ou existem vários tipos de ducados, ou se trata de um conceito artificial de contabilidade?". Havia conceitos contábeis no comércio de escravos do Oeste africano e em outros comércios do mundo que não possuíam qualquer representação tangível. Então, de repente, enquanto eu lia Greif, seus ducados pareciam precisar de um capítulo inteiro dedicado só a eles. Quem estava controlando as taxas de câmbio? Que tipo de sistema de preços foi esse? Acredito que possam existir caminhos muito interessantes para relacionar os espaços naquele trabalho aos tipos de questões que todos nós estamos levantando na antropologia.

FN - Neste sentido, e num tópico empírico e teórico muito similar, há também o seu diálogo com o historiador Akinobu Kuroda.

Kuroda! Este é um dos aspectos que esqueci de mencionar a respeito de Marginal gains. Bem, depois de sua publicação, Kuroda me procurou em função de seu trabalho sobre múltiplas economias monetárias, me convidando para juntar-me a eles, pois não tinham ninguém trabalhando na África. Ele estava trabalhando na China, e escreveu um artigo muito inspirador sobre Maria Theresa Thaler no norte da África 
(Kuroda 2007). Ele organizou uma rede de acadêmicos que trabalham com vários sistemas monetários do passado, incluindo o seu próprio trabalho sobre a história da moeda chinesa e japonesa, e também outros sobre a Índia, a Escandinávia, a Itália e algumas economias importantes, as grandes economias, até mesmo sobre a integração monetária do Império Romano. Porque havia casas da moeda em diferentes partes do Império, a pergunta era: eles estariam cunhando as mesmas moedas que estavam sendo cunhadas no centro? Ou essas regiões independentes estariam produzindo moedas com as mesmas palavras e os mesmos valores numéricos e cálculos anexados a elas, mas fisicamente diferentes em algum aspecto? E quem controlava isso? Esse acadêmico tradicional estava levantando estas questões extremamente interessantes.

Então, Kuroda me colocou nesta rede e eu fui a muitas de suas conferências e tem sido absolutamente inspirador, porque eles estão tentando montar uma abordagem teórica mais geral que dê conta de vários sistemas monetários. Olhar para suas combinações, olhar para as suas historicidades comuns, se existem estruturas de autoridade particulares associadas a eles, estruturas institucionais específicas. Alguns possuíam sistemas legais muito desenvolvidos e outros não, e então, como é que isso funcionava? Fazendo estas perguntas muito importantes, ele me encorajou a retomar a linha da articulação. Nessa linha de pensamento sobre sistemas de moedas fortes e fracas, devemos apenas pensar em nós mesmos como se vivêssemos em um sistema de moeda múltipla, no qual existem níveis diferentes de moedas que circulam de diferentes maneiras fazendo diferentes tipos de coisas? Mesmo no sistema monetário oficial, o que as pessoas usam pode não estar sendo necessariamente contabilizado.
FN - O que significa o "mercado" nesse contexto de múltiplos sistemas de moedas? E quanto ao "mercado" no âmbito da pluralidade do dinheiro?

O "mercado", sim. Parece-me que a disciplina da antropologia deveria ter assumido a questão da história mundial dos mercados. Nós permitimos, de certa maneira, que os economistas simplesmente equacionassem o mercado com o capitalismo, que é uma coisa muito estranha de se ter permitido. Quero dizer que, depois de Trade and market in the early empires e a classificação que Polanyi e seus colegas levaram adiante, tem havido uma quantidade enorme de pesquisa em arqueologia etc. e também em sistemas de mercados por toda parte. Será que temos uma teoria desses sistemas de mercado ou ao menos uma compilação empírica sobre que tipos de relações de troca têm havido? Eu estava perguntando a um colega que trabalhou na América Central, mais uma vez, sobre estas pequenas questões que permanecem em sua mente durante anos até que você encontre a resposta. Mercadorias foram distribuídas, mas não foram todas distribuídas através de sistemas de tributo políticos; pode não ter sido assim. E é possível encontrar no sul dos Estados Unidos peças e pedaços arqueológicos vindos do México, vindos da Guatemala, e assim por diante.

Eu me recordo muito particularmente de ter ouvido sobre um trabalho a respeito da distribuição de obsidiana, que era a lâmina principal desde a economia do metal de ouro e prata. Então, eu pensava comigo mesma, será que estes arqueólogos chamam a obsidiana de mercadoria? Até no modo como a descrevem, ao relatarem suas descobertas arqueológicas, eles pensam na obsidiana como uma mercadoria? Como isso é pensado por eles? Eu não fui adiante com esta pergunta. Este é o tipo de coisa que penso 
que os antropólogos podem fazer para iluminar o mercado e sua história mundial. Temos que viver por um longo tempo para dar conta de tema tão vasto... Bem, não estamos em número suficientemente grande, somos um grupo muito pequeno, e é por isso que os nossos encontros são tão importantes, pois assim nós começamos a cruzar as nossas ideias e a falar em sintonia com as agendas uns dos outros, de modo que amplifique o campo inteiro. Pois eu duvido que haja tantos antropólogos econômicos em todo o mundo quanto há economistas no Banco Mundial.

FN - Como você nos disse, seu campo de pesquisa na África Ocidental estava enredado em crises econômicas, inflação, instabilidade da moeda etc. De que maneira você acha que a sua pesquisa empírica e sua perspectiva teórica foram capazes de nos ajudar a pensar melhor (ou de modo diferente) sobre alguns problemas da nossa contemporaneidade, problemas que estão ligados à "crise econômica", à escassez de dinheiro, à multiplicação de moedas e aos processos sociais da formação dos preços?

A pesquisa etnográfica coloca em evidência alguns fenômenos particulares devido à sua importância para as pessoas envolvidas neste trabalho. Nós, então, pensamos de forma mais ampla: seria esta uma instância de algo maior? Isto é historicamente específico ou a nossa literatura contém outros casos semelhantes do passado e de outros lugares? O que nós vemos como comparável e por quê? Em seguida - tendo preenchido nossos próprios requisitos imaginativos disciplinares através da observação de outras situações (por exemplo, através da imprensa e de outras fontes), por meio da discussão com os colegas, e lendo a nossa biblioteca e arquivos de fontes - nós escolhemos uma perspectiva que possa iluminar o que ve- mos de mais potente nesses fenômenos, $\mathrm{o}$ que ultrapassa o nosso caso particular. Na economia monetária atual, eu argumentei que a diferenciação entre moeda "forte" e "fraca" nos oferece certa perspectiva, uma vez que, necessariamente, faz referência a um sistema monetário internacional, pode traçar relações entre os casos num sentido literal e histórico. Isto também implica uma atenção comparativa entre muitos casos de instabilidade e suas mediações no mundo.

Isto torna disponível toda a literatura histórico-teórica sobre dinheiro, a partir das clássicas "quatro funções" (meio de troca, meios de pagamento, unidade de conta e de valor), para aplicação e nuances críticas a partir de nossas atuais condições de mercados de dinheiro e financiamento. O mundo do dinheiro tornou-se imensamente complexo e extraordinariamente poderoso. Enquanto modos de câmbio no mercado se expandem, cada vez mais aspectos das relações que as pessoas têm umas com as outras são permeados. Como diz uma propaganda de banco vista em muitos aeroportos: "em breve não haverá mais mercado sobrando para emergir". Eu acho que a aproximação via distinção entre moeda forte/fraca, que é geralmente aceita como operacional no mundo, nos permite dar atenção a processos que ocorrem em diferentes níveis, e com tipos distintos de inclusão na vida social, mantendo a capacidade de fazer ligações entre eles, por vezes se distanciando ou então se aproximando para focar em pequenos detalhes.

FN - Depois de estudar o valor das moedas e das trocas monetárias, situações de moedas múltiplas, conversões de escalas e medidas, você chegou a uma proposta para uma nova agenda de pesquisa para a antropologia econômica (ou para a antropologia em geral). Poderia nos explicar os principais pontos desta agenda? 
Tenho em mente uma série de iniciativas nas quais estarei trabalhando e tentando encorajar. Todas essas iniciativas estão preocupadas com a forma de reestabelecer o estudo da economia no estudo da vida social, organizações sociais e modos culturais de desenho sobre o passado, herdando legados e aspirando em direção ao futuro. O conteúdo exato e as ênfases de cada trabalho dependem dos colegas que querem se juntar a mim ou ter o meu suporte, para que - eles próprios - liderem o caminho através de pontos da minha "agenda" que se cruzam com as suas próprias investigações. Na minha idade e neste estágio da minha carreira, estou comprometida com a promoção de liderança para a próxima geração, então eu raramente escolho e dirijo o tema em questão.

Uma exceção é um debate que organizei para o workshop de Joanesburgo em Teoria e Crítica deste ano, em torno da questão da "confusão" na vida social e expressiva. Mas foi um debate, não uma palestra. Outro exemplo é a minha escolha do tema geral da "Real Economy" (economia real), mas apenas como um conceito guarda-chuva para uma rede de pesquisadores do sul que escolhem a partir de seus interesses os seus próprios temas e tópicos específicos. Fora isso, estou trabalhando em uma colaboração para uma possível conferência sobre teoria, para abordar a interseção atual de economia, história econômica e antropologia econômica. E estou dando consultoria para dois grupos que estão desenvolvendo seus próprios projetos etnográficos sobre $\mathrm{o}$ dinheiro. É bastante estimulante que estes tópicos estejam instigando os futuros trabalhos de tantos estudiosos de uma geração mais jovem. Eu acho que o velho tema da sociedade-e-economia nunca foi tão desafiador como no momento presente.

\section{Referências bibliográficas}

GUYER, Jane I. 1981. "Household and community in African studies". African Studies Review, 24(3/4):87-137.

. (ed.). 1987a. Feeding African cities: studies in regional social history. Bloomington and Indianapolis: Indianapolis University Press.

1987b. "Feeding Yaoundé, capital of Cameroon". In: Feeding African cities Bloomington and Indianapolis: Indianapolis University Press. pp. 112-153.

(ed.). 1995. Money matters: instability, values, and social payments in the modern history of West African communities. Portsmouth: Heinemann.

1997. "Endowments and assets: the anthropology of wealth and the economics of intrahousehold allocation". In: Lawrence Haddad, John Hoddinott \& Harold Alderman (eds.), Intrahousehold resource allocation in developing countries: models, methods and policy. Baltimore: John Hopkins University Press. pp. 112-125. 1999. "Anthropology: the study of social and cultural originality". African Sociological Review, 3(2):149-154.

2004. Marginal gains: monetary transactions in Atlantic Africa. Chicago: University of Chicago Press.

2007a. "Africa has never been 'traditional': so can we make a general case?". African Studies Review, 50(2):183-202.

2007b. "Prophecy and the near future: thoughts on macroeconomic, evangelical and punctuated time". American Ethnologist, 34(3): 409-450.

\& BELINGA, Samuel M. Eno. 1995. "Wealth in people as wealth in knowledge: accumulation and composition in Equatorial Africa". The Journal of African History, 36(1):91-120.

$\therefore$ DENZER, LaRay \& AGBAJE, Adigun (eds.). 2002. Money struggles and city life: devaluation in Ibadan and other urban centers in Southern Nigeria, 1986-1996. Portsmouth NH: Heineman.

KURODA, Akinobu. 2007. "The Maria Theresa dollar in the early twentieth-century Red Sea region: a complementary interface between multiple markets". Financial History Review, 14(1):89-110. 